\title{
HELICOBACTER PYLORI INFECTION AND BRAIN DYSFUNCTION
}

Helicobacter pylori infection was identified in 5 children with severe neurologic impairment who underwent upper gi endoscopy at the Alfred I duPont Institute, Wilmington, De, and Jefferson Medical College, Philadelphia. Subsequently, patients with severe neurologic impairments, such as cerebral palsy and head trauma, who had endoscopies because of gastrointestinal symptoms were examined for $H$. pylori infection in gastric antral mucosa biopsies. Of 61 examined, 7 (11\%) were positive for infection and had gastritis. Institutionalized patients were at much greater risk of infection than those seen as outpatients (75\% cf 7\%). Resolution of gi symptoms (emesis, guiacpositive stools, refusal to eat, and irritability during feedings) was complete in 6 of the 12 infected patients and partial in 4 after antibiotic treatment. (Proujansky R et al. Symptomatic Helicobacter pylori infection in young patients with severe neurologic impairment. I Pediatr Nov 1994;125:750-752). (Reprints: Roy Proujansky MD, Alfred I duPont Institute, 1600 Rockland Rd, Wilmington, DE 19899).

COMMENT. All neurologically impaired, and especially institutionalized, children with persistent gastrointestinal symptoms should be examined and treated when positive for $H$. pylori infection.

A possible $H$. pylori infection should be considered in children with epilepsy who develop gastritis and feeding difficulties after longterm treatment with valproic acid, divalproex sodium, and other antiepileptic drugs. (see Progress in Pediatric Neurology I, PNB Publishers, 1991). Gastritis and gastric ulceration attributed to the antiepileptic drugs may be due primarily to infection in the gastric mucosa.

\section{NEOPLASTIC DISORDERS}

\section{OUTCOME OF OPSOCLONUS WITH NEUROBLASTOMA}

The neurologic and developmental outcomes in 10 children with opsoclonus-myoclonus ("dancing eyes syndrome") and neuroblastoma were reviewed by examination of records at Northwestern University Medical School and Children's Memorial Hospital, and the University of Illinois Hospital, Chicago. Ages ranged from 8 months to 30 months. Opsoclonus and ataxia had been present from 6 days to 1 year before diagnosis of neuroblastoma. All had localized disease and 50\% had extraabdominal tumors. All are alive and without recurrence of tumor 8 months to 111 months after resection. All had opsoclonus-myoclonus or ataxia for at least 5 months after surgery, but eventually responded to ACTH therapy. Two were symptom-free 12 months after surgery, and 3 remitted after 36 months. Nine relapsed and had chronic deficits, including cognitive and motor delays, reading and language deficits, and behavioral abnormalities. Factors precipitating recurrences of opsoclonus-myoclonus or ataxia included discontinuance or reduction of ACTH, febrile illness, and immunizations. (Koh PS, Raffensperger JG et al. Long-term outcome in children with opsoclonus-myoclonus and ataxia and coincident neuroblastoma. I Pediatr Nov 1994;125:712-716). (Reprints: John G Raffensperger MD, Pediatric Surgery, Children's Memorial Hospital, 2300 Children's Plaza, Chicago, IL 60614). 